\title{
Preparation and characterization of electrically conductive composites of poly(vinyl alcohol)-g-poly(acrylic acid) hydrogels impregnated with polyaniline (PANI)
}

\author{
A. K. Bajpai*, J. Bajpai, S. N. Soni \\ Bose Memorial Research Laboratory, Department of Chemistry, Government Autonomous Science College, \\ Jabalpur, 482001 (M.P.), India
}

Received 21 August 2007; accepted in revised form 2 November 2007

\begin{abstract}
Novel electrically conducting composite materials consisting of poly(aniline) (PANI) nanoparticles dispersed in a poly(vinyl alcohol) (PVA)-g-poly(acrylic acid) (PAA) hydrogels were prepared within the polymer matrix by in situ polymerization of aniline. The conversion yield of aniline into PANI particles was determined gravimetrically while structural confirmation of the synthesized polymer was sought by Fourier Transform Infrared (FTIR), UV-visible analysis and $\mathrm{X}$-ray diffraction (XRD) technique. Morphology and dimension of PANI particles embedded into the colored optically semi-transparent hydrogels were evaluated by Scanning Electron Microscopy (SEM) analysis. Electrical conductivity of composite hydrogels of different composition was determined by LCR meter while electroactive behavior of composite hydrogels swollen in electrolyte solution was investigated by Effective Bend Angle (EBA) measurements.
\end{abstract}

Keywords: smart polymers, polymer composites, conducting polymers

\section{Introduction}

A thermodynamic system capable of transforming chemical energy directly into mechanical work is known as a chemo-mechanical system. Many artificial chemo-mechanical systems made of environmentally sensitive polymer gels are being developed for sensor/actuator system such as controllable membrane separation system and electrically regulated drug delivery system [1].

A gel containing ionic groups can be actuated isothermally by an electric field. When the gel is negatively charged, it swells near the anode and contracts near the cathode, the contraction rate being proportional to the external electric current [2].

The absolute change in volume is by no means insignificant-dimensional changes of say some percents are quite usual. Such a gel bar made of polyelectrolyte materials can bend backwards and forward by the application of an electric field. Water and ions migrate towards the electrode bearing a change opposite in sign to the net change in the gel, and this coupling of electro-osmosis and electrophoresis is thought to be responsible for the observed chemo-mechanical behavior [3].

Electrically conducting polymers (ECPs) and in particular polyaniline, polypyrrole, polythiophene and their derivatives have been the subject of intensive research for their unique electrical, electrochemical and/or optical properties [4-5] and uncountable applications [6-10]. ECPs are also named 'conjugated polymers' because they are macromolecules containing a spatially extended $\pi$ bonding system, which is the reason of their intrinsic semiconducting nature.

Polyaniline is the one of the most promising conducting polymers due to a good combination of

*Corresponding author, e-mail: akbmrl@yahoo.co.in

(C) BME-PT and GTE 
properties, stability, price and ease of synthesis by different routes [11-22]. It exists in a variety of reversible protonated and oxidized forms, differing for electrical, electrochemical and/or optical properties like many ECPs [23-25]. PANI is difficult to process because it is soluble only in a limited number of organic solvents.

Electrically conducting polymers can be prepared by the polymerization of aniline in acidic medium, resulting in the formation of polyaniline (PANI) [26]. Influence of polymerization parameters on the molecular weight of polyaniline has been studied [27] and a new aggregation mechanism for shape and aggregation control of PANI nanoparticles was suggested [28]. PANI is known as being stable, most promising, and of low cost so different synthetic routes have been developed like one phase emulsion polymerization process [29], Triton Y-100 [30], potentiometric method [31], polymerization by different oxidizing agents like cupric sulphate [32], iron (III) chlroide [33]. PANI nanowires have also been potentiostatically deposited on a stainless steel electrode [34]. The polymerization process for PANI and poly(2-methoxy-aniline) (POMA) nanotubes formation was also investigated [35]. Electrically conducting hydrogel composites made of PANI nanoparticles and poly $(\mathrm{H}-$ vinyl-O-/m amino acetophenone of different compositions were synthesized by oxidative polymerization $[36,37]$. PANI powder with crystalline semi-conducting $\mathrm{ZnS}$ composite by mechanical mixing was also found to increase conductivity [38], Similarly, PANI/ $/ \mathrm{Co}_{3} \mathrm{O}_{4}$ was synthesized [39] to overcome the solubility problem of PANI. Lee et al. [40] reported direct patterning of conducting water-soluble polymers. Some more aspects of preparation methods and properties of polyaniline blends and composites with organic polymer have also been reviewed [41].

Thus, being motivated by the significant and diversified applications of PANI and related conducting polymers, the present paper aims at synthesizing a PANI impregnated graft copolymer PVA-g-PAA and characterizing it by various analytical techniques such as FTIR, SEM and UV-visible analysis. The selection of PVA and PAA as the hydrogels components of the polymer matrix lies in their unlimited applications in medicine, biology and technology [42-44]. The present paper also describes the results on electroactive behavior of the graft copolymer impregnated with PANI molecules.

\section{Experimental}

\subsection{Materials}

Polyvinyl alcohol (PVA) (98.6\% hydrolyzed) was obtained from Research Lab, Mumbai, India and used as received. Acrylic acid (AA) was purchased from Merck Limited (Mumbai, India) and purified by vacuum distillation at $55^{\circ} \mathrm{C}$. Other chemicals such as aniline (AN), hydrochloric acid, potassium persulphate (KPS), ammonium persulphate (APS), $\mathrm{N}, \mathrm{N}^{\prime}$-methylene bis acrylamide (MBA) were also of analytical grade and used without any further purification.

\subsection{Methods}

\subsubsection{Preparation of gel}

A polymer matrix composed of PVA-g-PAA was prepared by using MBA as crosslinker and KPS as polymerizing initiator. Schematically, the reaction mechanism may be displayed as shown in Figure 1. In a typical experiment, $1 \mathrm{~g}$ PVA was dissolved in $25 \mathrm{ml}$ of hot double distilled water and to this solution were added precalculated amounts of acrylic acid $(43.7 \mathrm{mM})$, MBA $\left(19.45 \cdot 10^{-2} \mathrm{mM}\right)$ and KPS $\left(11.10 \cdot 10^{-2} \mathrm{mM}\right)$. The whole reaction mixture was homogenized and kept in a petri dish (corning glass, $2.5^{\prime \prime}$ diameter) maintained at $35 \pm 0.2^{\circ} \mathrm{C}$ for $24 \mathrm{~h}$. After the reaction is over, the whole mass converted into a semi-transparent film and it was purified by equilibrating it in double distilled water for a week. The swollen gel was dried at room tem-

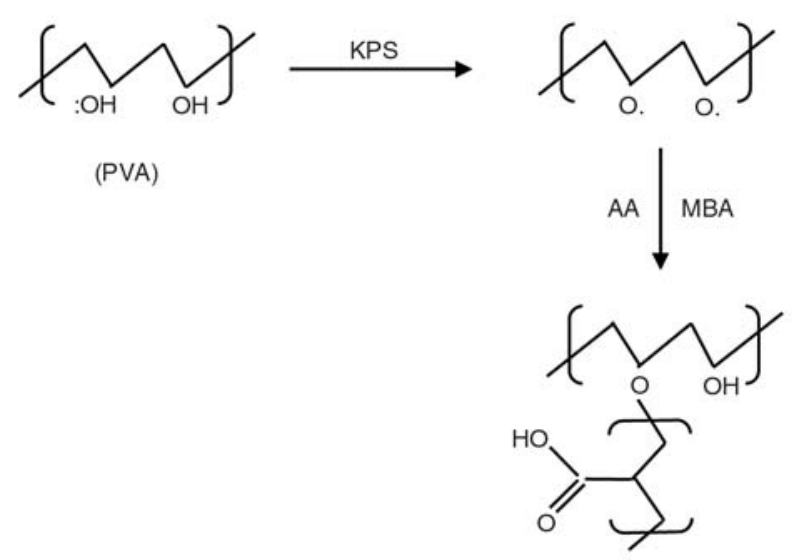

Figure 1. A reaction scheme for graft co-polymerization of PAA onto PVA 
perature, cut into rectangular size piece and stored in airtight plastic bags.

\subsubsection{PANI impregnation}

Required quantity of AN (10.74 mM) was dissolved in $0.5 \mathrm{~N} \mathrm{HCl}(50 \mathrm{ml})$ and the gel prepared was allowed to soak in the AN solution for $24 \mathrm{~h}$. The aniline (AN) containing swollen gel was dried and then again left in a $0.3 \mathrm{M}$ APS bath to soak required quantity of APS in solution $(0.5 \mathrm{~N} \mathrm{HCl})$. As soon as the gel swells in APS solution, the entrapped APS initiates polymerization of AN via the mechanism shown in Figure 2.

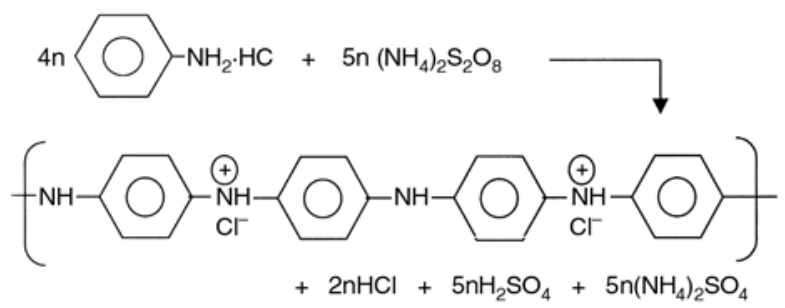

Figure 2. Reaction scheme showing the polymerization of aniline

As the polymerization progresses, the semi-transparent gel turns into black. The PANI impregnated gel is repeatedly washed with distilled water and allowed to dry at $30 \pm 0.2^{\circ} \mathrm{C}$ for $72 \mathrm{~h}$.

The percentage impregnation of PANI into the gel was calculated by the Equation (1):

[\%] Impregnation of PANI $=\left(\frac{W_{P A N I}-W_{D r y}}{W_{D r y}}\right) \cdot 100$

where, $W_{P A N I}$ is weight of the dry PANI impregnated gel and $W_{D r y}$ is the initial weight of polymer gel.

In order to achieve the objectives undertaken in the study, hydrogels of different composition were prepared by varying the amounts of PVA, AA, MBA, KPS, AN and APS in the feed mixture of the hydrogel.

\subsection{Characterization}

\subsubsection{Fourier Transform Infrared (FTIR) spectra}

To gain insights into the structural information of the prepared PANI impregnated gel, the FTIR spectra of PANI powder, polymer hydrogels and PANIimpregnated matrix were recorded in a FTIR spectrophotometer (FTIR-8400S, Shimadzu). For recording FTIR spectra of native and PANI impregnated films, quite thin and transparent films of respective samples were prepared by solution casting method and the prepared films were directly mounted on spectrophotometer.

\subsubsection{UV-visible analysis}

UV-visible analysis was also carried out on a double beam UV-VIS spectrophotometer (Systronics, 2201, Ahemdabad, India). For scanning UV-spectra, thin films of samples (native and PANI impregnated) were prepared of sizes $3 \times 1 \times 0.05 \mathrm{~cm}^{3}$ by solution casting method and put in to the quartz cuvette in vertical orientation.

\subsubsection{X-ray diffraction (XRD) analysis}

In order to gain insights into the crystalline nature of the prepared native and PANI impregnated gel, the X-ray diffraction spectra were recorded using a Philips (Holland) automated X-ray powder diffractometer. The dried gels were placed on the glass slide specimen holder and exposed to X-rays in a vertical goniometer assembly. The scan was taken between 10 to $90^{\circ}$ with a scanning speed of $2.4^{\circ} \cdot \mathrm{min}^{-1}$. The operating target voltage was $35 \mathrm{kV}$, tube current was $20 \mathrm{~mA}$ and radiation used was $\mathrm{FeK}_{\alpha}(\lambda=0.193 \mathrm{~nm})$.

\subsubsection{Particle size analysis}

The distribution of particle size of prepared PANI powder was measured by a particle size analyser (Fritsch Particle Sizer Analysette). The PANI particles were prepared as described below:

A known quantity of aniline $\left(10.74 \cdot 10^{-2} \mathrm{mM}\right)$ was dissolved into $50 \mathrm{ml}$ of $0.5 \mathrm{~N} \mathrm{HCl}$ and to this solution of aniline was added $0.3 \mathrm{M}$ APS. The reaction mixture was kept for polymerization at room temperature for $24 \mathrm{hrs}$ and the resulting polyaniline precipitate was filtered, washed and dried at $35^{\circ} \mathrm{C}$ for $24 \mathrm{hrs}$. The PANI powder so prepared was stored in airtight polythene bags.

\subsubsection{Scanning Electron Microscopy (SEM) analysis}

The SEM of the prepared native and PANI impregnated gels were recorded on a scanning electron microscope (Philips 515) for their surface morphological structure. 


\subsubsection{Electrical conductivity}

The electrical conductivity of prepared gels were measured by Four probe LCR meter (Masstech Digital M/M No. MAS 830L) with the help of silver electrode pressed on both sides of the gel. The electrical conductivity of gels of different compositions was also measured.

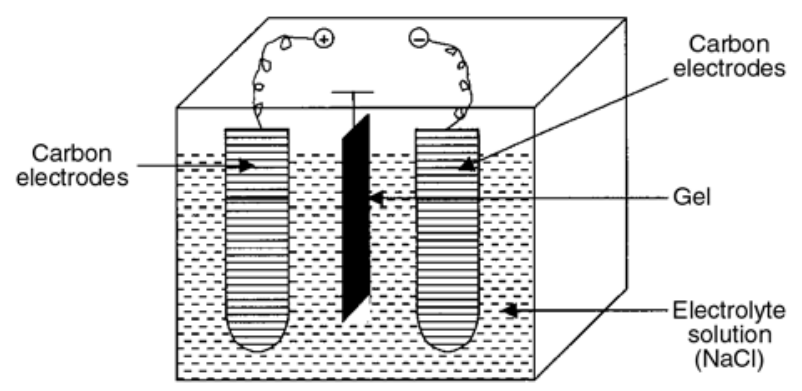

Figure 3. A home-made apparatus for measuring effective bend angle

\subsubsection{Effective Bend Angle (EBA) analysis}

In order to demonstrate the sensitivity of the gel to the applied external electric field, the bending of the gel under the applied field was measured using a home-made device as shown in Figure 3.

Samples were prepared with varying PANI impregnation percentage and allowed to attain equilibrium swelling in the $\mathrm{NaCl}$ aqueous solution at room temperature before electrical stimulation. The same solution was taken in the glass case equipped with two parallel carbon electrodes fixed $30 \mathrm{~mm}$ apart at the centre of the glass case. A rectangular specimen having dimensions of $15 \times 1 \times 1 \mathrm{~mm}^{3}$ was cut and placed vertically at the center of the two electrodes fixing one end of the specimen at the top. The DC voltage was applied across the solution between electrodes and the equilibrium-bending angle was measured with a protractor.

\subsubsection{Reproducibility of data}

All measurements were carried out at least thrice and average value was utilized for presentation of results. It was found that the experimental errors had never been greater than $1 \%$.

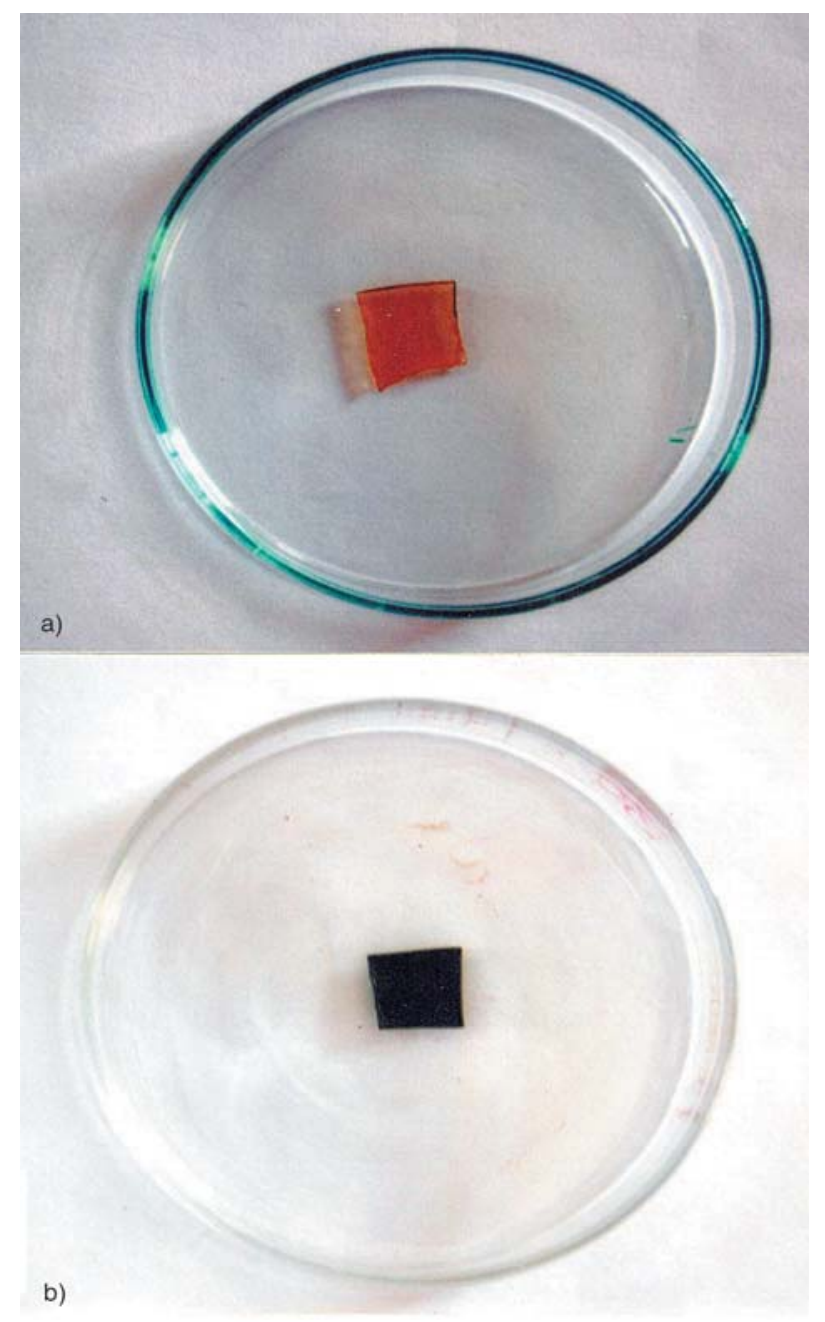

Figure 4. Physical appearance of (a) PVA-g-PAA gel and (b) PANI impregnated PVA-g-PAA gel

\section{Results and discussion}

\subsection{Characterization of gels}

\subsubsection{Physical appearance}

Figures $4 \mathrm{a}$ and $\mathrm{b}$ depict appearance of the native and PANI impregnated gels which provide a clear evidence of impregnation of PANI into the polymer gel matrix. As evident from the photographs, whereas the native gel is semi-transparent in color while the impregnated gel appears dark-green, which could be attributed to the formation of PANI within the matrix.

\subsubsection{FTIR spectra}

Figures 5a and $\mathrm{b}$ represent FTIR spectra of PVA and PVA-g-PAA polymer films, respectively scanned in the range $400-4000 \mathrm{~cm}^{-1}$. The characteristic peaks at $1730-1854 \mathrm{~cm}^{-1}$ are due to the pres- 


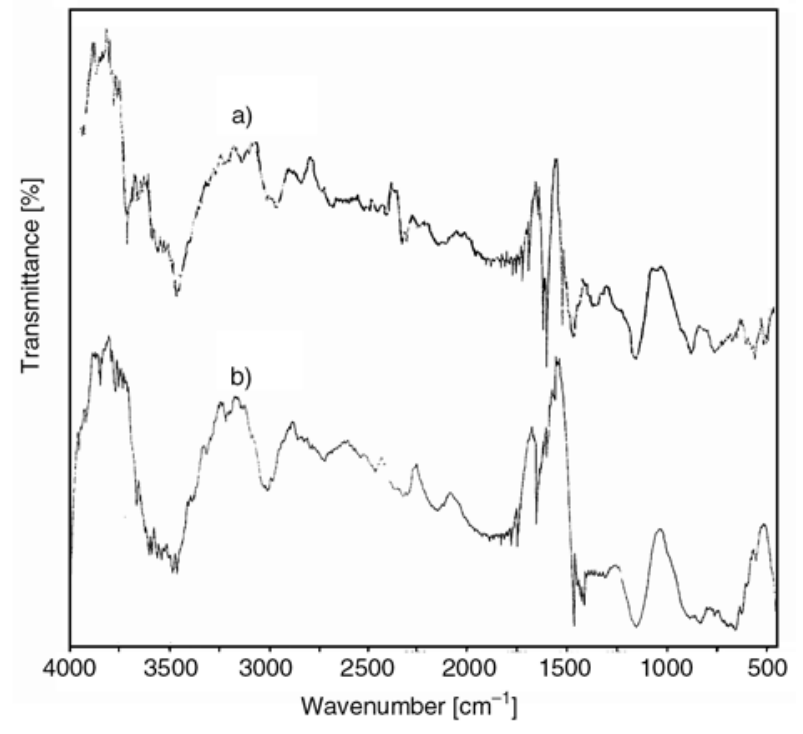

Figure 5. FTIR spectra of (a) PVA and (b) PVA-g-PAA gel

ence of $\mathrm{C}=\mathrm{O}$ stretching vibration and the peak observed at $650 \mathrm{~cm}^{-1}$ is due to the $\mathrm{OH}$ out of plane vibration of the carboxylic groups of PAA which appears in the spectra of grafted polymers only, i. e., PVA-g-PAA (Figure 5b). This obviously confirms the grafting reaction. The characteristic peaks at 3468 and $3473 \mathrm{~cm}^{-1}$ in both the spectra (a) and (b) are due to the presence of $\mathrm{OH}$ groups of PVA, while the spectral bands between 3470 and $3600 \mathrm{~cm}^{-1}$ are due to $\mathrm{OH}$ stretching vibration of PVA and PAA, respectively, which also confirm the grafting of

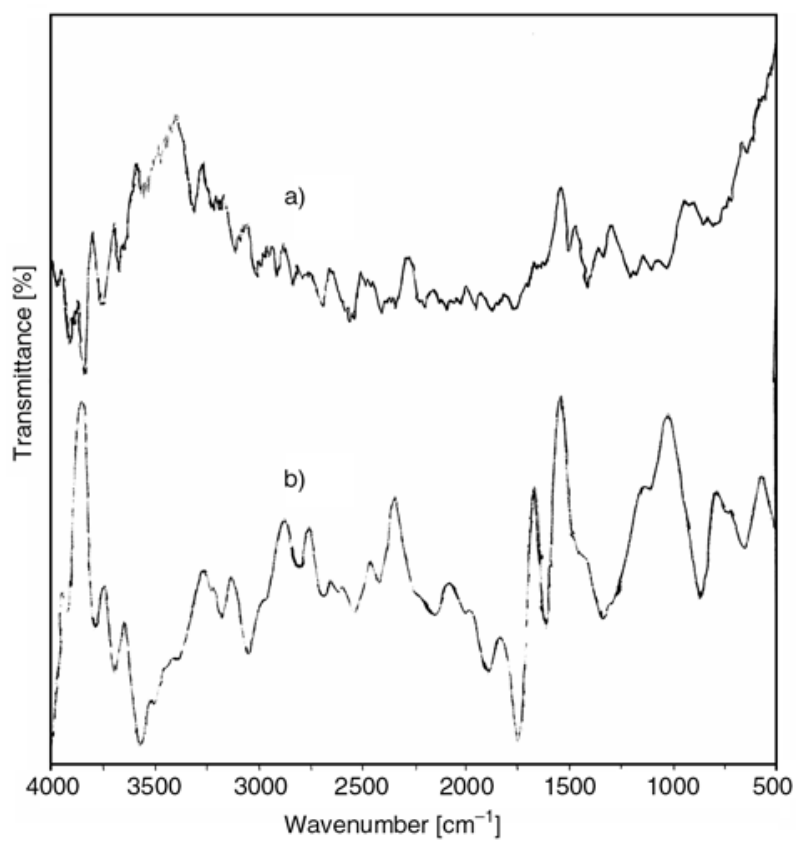

Figure 6. FTIR spectra of (a) PANI powder and (b) PVA-g-PAA impregnated PANI gel
PAA into PVA. The characteristic peak at $1162 \mathrm{~cm}^{-1}$ is due to the formation of acetal ring.

Figures $6 \mathrm{a}$ and $\mathrm{b}$ represent the FTIR spectra of PANI powder and PANI impregnated PVA-g-PAA gel film. The characteristic peaks in Figure 6a appearing at 824, 1144 and 1312, 1505, and $1590 \mathrm{~cm}^{-1}$ indicate aromatic $\mathrm{C}-\mathrm{H}$, aromatic amide, and aromatic $\mathrm{C}-\mathrm{C}$ stretching vibrations, respectively. The spectra (b) of PANI impregnated PVAg-PAA gel film contain peaks at 876, 1150, 1347, 1500 and $1614 \mathrm{~cm}^{-1}$ indicating the presence of aromatic $\mathrm{C}-\mathrm{H}$, aromatic amide, and aromatic $\mathrm{C}-\mathrm{C}$ stretching vibrations which confirm the impregnation of PANI into the gel (polymer matrix).

\subsubsection{UV-visible spectral analysis}

The UV-visible analysis of PVA-g-PAA film and PANI impregnated PVA-g-PAA film was carried out in the range of 200 to $800 \mathrm{~nm}$. It is observed that two characteristic peaks at 334 and at 632 in PANI impregnated PVA-g-PAA film spectra (Figure 7b) indicates the presence of PANI into the gel whereas these peaks are not visible in the spectra of PVA-g-PAA (Figure 7a). This obviously confirms the impregnation of PANI into the gel because the emeraldine form of PANI has two characteristic peaks at 334 and $632 \mathrm{~nm}$ originating from $\pi-\pi^{*}$ transition of benzenoid rings and the exciton absorption of the quinoid rings, respectively.
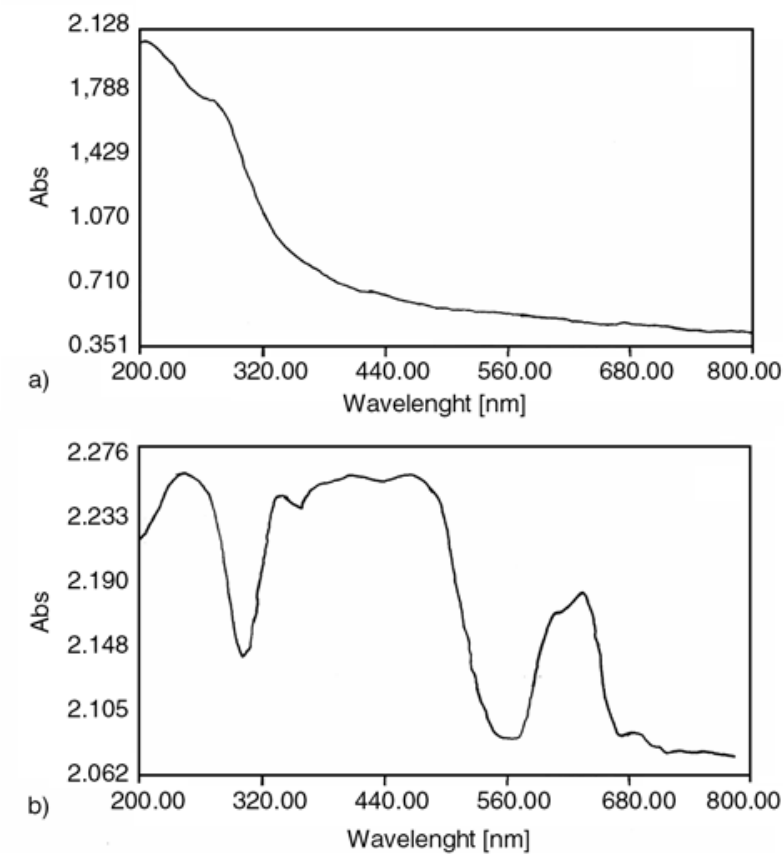

Figure 7. UV-visible spectra of (a) native (PVA-g-PAA) gel and (b) PANI impregnated gel 


\subsubsection{X-ray diffraction analysis}

The XRD patterns of the prepared native and PANI impregnated gels are shown in Figures $8 \mathrm{a}$ and $\mathrm{b}$, respectively. Figure 8 a shows a prominent peak near $20^{\circ}$, which corresponds to the (101) plane of the PVA crystal. Other minor peaks around 21 and $22^{\circ}$ could be attributed to minor crystallites of grafted polyacrylic acid chains.

The diffraction patterns of PANI impregnated gel are shown in Figure $8 \mathrm{~b}$ which not only shows a characteristic peak at $20^{\circ}$ (due to PVA) but also depicts a prominent peak at $25^{\circ}$, which is a characteristic peak of PANI. Thus, the XRD-patterns of impregnated gel provides an additional evidence of PANI formation within the polymer matrix.

A comparison of the peak area of the two diffractograms clearly indicates that upon PANI impregnation, the polymer matrix looses its crystallinity as evident from the increase in broadness of the XRD spectra (b). The loss in crystallinity due to PANI impregnation may be explained by the fact that because of in situ polymerization of aniline within the matrix, the PANI chains produced due to polymerization may bring disorder in the chains packing and, therefore, may result in a loss of crystallinity.
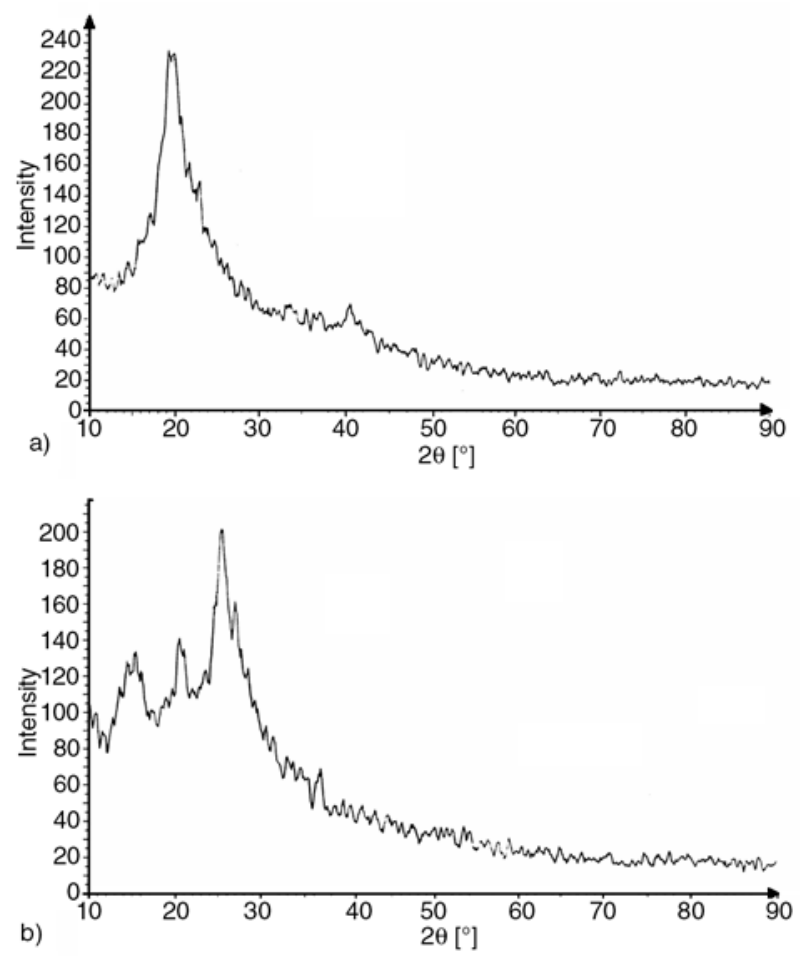

Figure 8. XRD-spectra of (a) native (PVA-g-PAA) gel and (b) PANI impregnated gel

\subsubsection{SEM}

The morphological features of the prepared native and PANI impregnated composite films have been studied by recording SEM images of the films as shown in Figure 9a and b, respectively. It is clear from the image (a) that the surface of the native gel is quite homogeneous and shows no cracks, voids or unevenness. This suggests that after grafting of polyacrylic acid chains onto PVA backbone, the matrix remains homogeneous in composition. However, impregnation of PANI into the matrix develops heterogeneity in the matrix as evident from the SEM image (b). It is clear from the image (b) that impregnated PANI molecules form clusters like morphology varying in the sizes 0.5 to $2 \mu \mathrm{m}$. The formation of PANI clusters within the polymer matrix could be attributed to hydrophobic nature of the PANI molecules, which may aggregate due to hydrophobic dispersion forces.

\subsubsection{Particle size analysis}

The particle size distribution curve of the prepared PANI powder is shown in Figure 10 which indicates that the size of the particles vary in the range
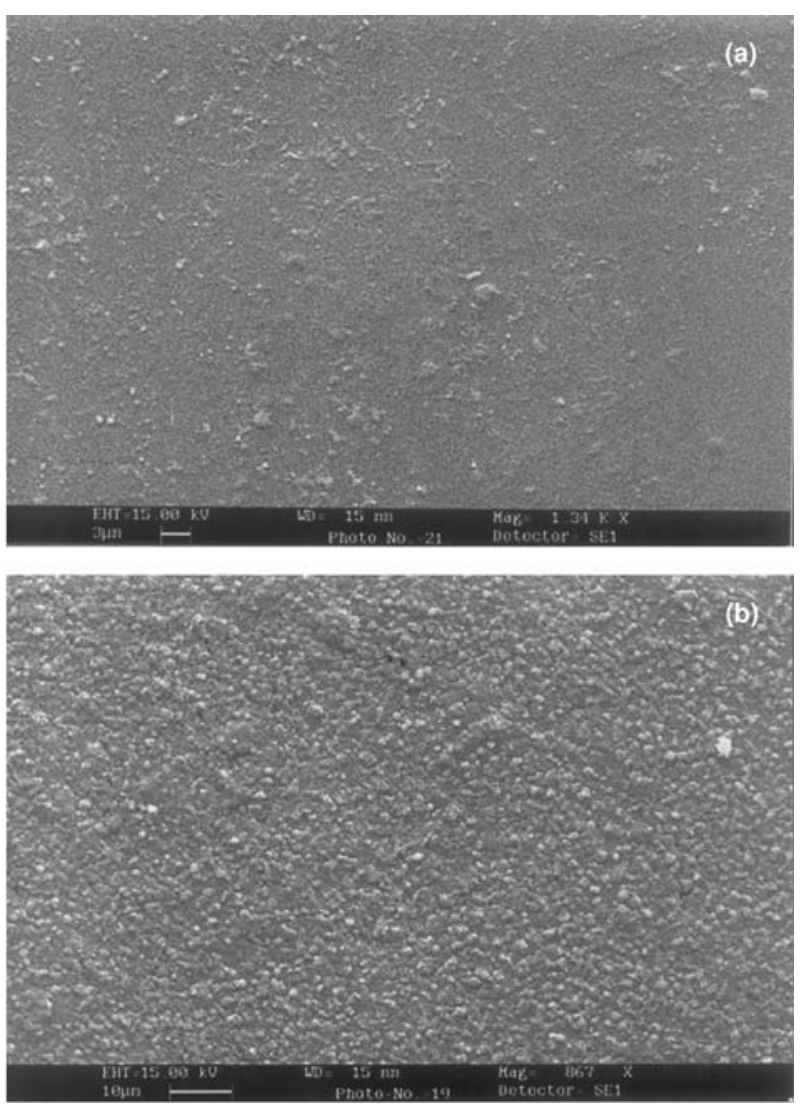

Figure 9. SEM image of (a) native (PVA-g-PAA) gel and (b) impregnated gel 


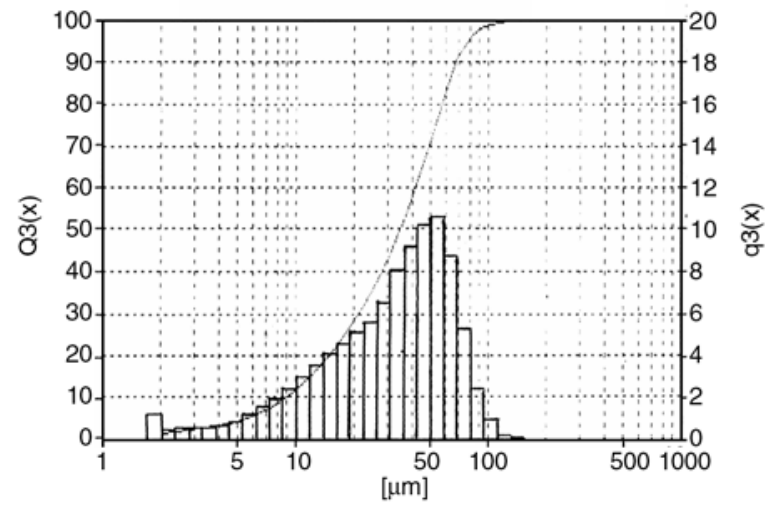

Figure 10. Particle size distribution curve of PANI powder

1 to $100 \mu \mathrm{m}$ and greatest fraction of particles possess a size of $50 \mu \mathrm{m}$. The variation in size of PANI particles could be attributed to varying degree of aggregation of particles under existing experimental conditions.

\subsection{PANI impregnation and effects of ingredients}

In the present study, AN has been taken as a monomer and in order to get it polymerized within the polymer matrix, it is essential that AN molecules should penetrate into the polymer gel. To achieve the desired objectives of AN polymerization, the monomer $\mathrm{AN}$ was dissolved in $\mathrm{HCl}$ which formed aniline hydrochloride, thus, yielding cationic species of AN. Now, because of positive charge over the AN molecule, its diffusion into the matrix will be controlled by operative electrostatic forces as well as swelling nature of the hydrogel matrix. It is important to notice here that the polymer matrix is hydrophilic in nature while AN molecules are hydrophobic. In this way one cannot expect hydrophobic/hydrophilic forces being mainly responsible for diffusion of AN. It is, therefore, convincing to consider electrostatic forces as the main factor to cause diffusion of AN into the polymer matrix. Moreover, the presence of PAA segments in the matrix will also contribute to the electrostatic interaction between the entering AN molecules and the matrix itself. Impregnation of PANI into the polymer matrix is basically dependent on the extent of swelling of the polymer film in aniline hydrochloride solution and its subsequent polymerization within the matrix. Thus, the inclusion of aniline into the polymer should definitely be a function of the chemical composition (and nature also) of the hydrogel and this has been investigated further by varying the concentration of the constituents components of the gel as discussed in the following para.

\subsubsection{Effect of PVA}

To study the effect of PVA on PANI impregnation, PVA was varied in the range 1.0 to $3.0 \mathrm{~g}$ keeping quantities of other ingredients constant. The results summarized in Table 1 reveal that the amount of impregnated PANI constantly increases with increasing PVA concentration in the gel up to $1.5 \mathrm{~g}$. The results may be explained by the fact that with increasing PVA, the hydrophilicity of the matrix increases that allows more aniline to enter into the matrix, which upon polymerization produces greater amount of PANI while beyond $1.5 \mathrm{~g}$ of PVA, PANI impregnation decreases. This is due to the fact that the increasing PVA content decreases the interionic repulsion between the PAA chain which allows lesser number of aniline molecules to enter the polymer matrix that results in a decrease in PANI impregnation.

\subsubsection{Effect of AA}

The influence of AA variation on the extent of PANI impregnation has been investigated by varying the concentration of $\mathrm{AA}$ in the range 14.6 to $43.7 \mathrm{mM}$ while keeping the other constituents concentration constant. The results are shown in Table 1, which indicate an increase in the impregnated amount of PANI with increasing PAA content. The increase in PANI impregnation may be explained by the fact that due to ionic nature of PAA, its increasing content in the gel results in interionic repulsion between the PAA chains, which permits a large number of AN molecules to enter the polymer matrix. This results in an enhanced impregnation.

\subsubsection{Effect of MBA}

The effect of increasing concentration of MBA on the extent of PANI impregnation has been studied by varying its concentration in the range $6.5 \cdot 10^{-2}$ to $25.9 \cdot 10^{-2} \mathrm{mM}$ while keeping the other concentration terms constant. The results are shown in Table 1, which show that the amount of impregnated PANI increases initially with the increasing 
Table 1. Effect of concentration of constituents of the gel on the amount of PANI impregnation

\begin{tabular}{|c|c|c|c|}
\hline PVA content $[\mathrm{g}]$ & PANI impregnation [\%] & & Other ingredients \\
\hline 1.0 & 3.57 & \multirow{4}{*}{\multicolumn{2}{|c|}{$\begin{array}{l}\text { AA }-29.1 \mathrm{mM} \\
\text { MBA }-13.0 \cdot 10^{-2} \mathrm{mM} \\
\text { KPS }-7.39 \cdot 10^{-2} \mathrm{mM} \\
\text { APS }-0.3 \mathrm{M} \text { in } 0.5 \mathrm{~N} \mathrm{HCl} \\
\text { AN }-10.74 \mathrm{mM} \text { in } 0.5 \mathrm{~N} \mathrm{HCl}\end{array}$}} \\
\hline 1.5 & 3.80 & & \\
\hline 2.0 & 3.37 & & \\
\hline 3.0 & 1.18 & & \\
\hline AA content [mM] & PANI impregnation [\%] & \multicolumn{2}{|r|}{ Other ingredients } \\
\hline 14.6 & 1.85 & \multirow{4}{*}{$\begin{array}{l}\text { PVA } \\
\text { MBA } \\
\text { KPS } \\
\text { APS } \\
\text { AN }\end{array}$} & \multirow{4}{*}{$\begin{array}{l}-1 \mathrm{~g} \\
-13.0 \cdot 10^{-2} \mathrm{mM} \\
-\quad 7.39 \cdot 10^{-2} \mathrm{mM} \\
-\quad 0.3 \mathrm{M} \text { in } 0.5 \mathrm{~N} \mathrm{HCl} \\
-10.74 \mathrm{mM} \text { in } 0.5 \mathrm{~N} \mathrm{HCl}\end{array}$} \\
\hline 29.1 & 3.57 & & \\
\hline 36.0 & 5.75 & & \\
\hline 43.7 & 7.55 & & \\
\hline MBA content [mM] & PANI impregnation [\%] & \multicolumn{2}{|r|}{ Other ingredients } \\
\hline $6.50 \cdot 10^{-2}$ & 12.50 & \multirow{4}{*}{$\begin{array}{l}\text { PVA } \\
\text { AA } \\
\text { KPS } \\
\text { APS } \\
\text { AN }\end{array}$} & \multirow{4}{*}{$\begin{array}{l}-1 \mathrm{~g} \\
-43.7 \mathrm{mM} \\
-\quad 7.39 \cdot 10^{-2} \mathrm{mM} \\
-\quad 0.3 \mathrm{M} \text { in } 0.5 \mathrm{~N} \mathrm{HCl} \\
-10.74 \mathrm{mM} \text { in } 0.5 \mathrm{~N} \mathrm{HCl}\end{array}$} \\
\hline $13.00 \cdot 10^{-2}$ & 6.48 & & \\
\hline $19.45 \cdot 10^{-2}$ & 32.69 & & \\
\hline $25.90 \cdot 10^{-2}$ & 19.05 & & \\
\hline KPS content $[\mathrm{mM}]$ & PANI impregnation [\%] & \multicolumn{2}{|r|}{ Other ingredients } \\
\hline $3.69 \cdot 10^{-2}$ & 4.35 & \multirow{4}{*}{$\begin{array}{l}\text { PVA } \\
\text { AA } \\
\text { MBA } \\
\text { APS } \\
\text { AN }\end{array}$} & \multirow{4}{*}{$\begin{array}{l}-1 \mathrm{~g} \\
-43.7 \mathrm{mM} \\
-19.45 \cdot 10^{-2} \mathrm{mM} \\
-\quad 0.3 \mathrm{M} \text { in } 0.5 \mathrm{~N} \mathrm{HCl} \\
-10.74 \mathrm{mM} \text { in } 0.5 \mathrm{~N} \mathrm{HCl}\end{array}$} \\
\hline $7.39 \cdot 10^{-2}$ & 4.07 & & \\
\hline $11.10 \cdot 10^{-2}$ & 10.00 & & \\
\hline $14.80 \cdot 10^{-2}$ & 3.26 & & \\
\hline AN content $[\mathrm{mM}]$ & PANI impregnation [\%] & \multicolumn{2}{|r|}{ Other ingredients } \\
\hline 5.30 & 6.25 & \multirow{4}{*}{$\begin{array}{l}\text { PVA } \\
\text { AA } \\
\text { MBA } \\
\text { KPS } \\
\text { APS }\end{array}$} & \multirow{4}{*}{$\begin{array}{l}-1 \mathrm{~g} \\
-43.7 \mathrm{mM} \\
-19.45 \cdot 10^{-2} \mathrm{mM} \\
-11.10 \cdot 10^{-2} \mathrm{mM} \\
-\quad 0.3 \mathrm{M} \text { in } 0.5 \mathrm{~N} \mathrm{HCl}\end{array}$} \\
\hline 10.74 & 9.40 & & \\
\hline 16.11 & 33.66 & & \\
\hline 21.48 & 6.70 & & \\
\hline APS concentration [M] & PANI impregnation [\%] & \multicolumn{2}{|r|}{ Other ingredients } \\
\hline 0.2 & 16.67 & \multirow{4}{*}{$\begin{array}{l}\text { PVA } \\
\text { AA } \\
\text { MBA } \\
\text { KPS } \\
\text { AN }\end{array}$} & \multirow{4}{*}{$\begin{array}{l}-1 \mathrm{~g} \\
-43.7 \mathrm{mM} \\
-19.45 \cdot 10^{-2} \mathrm{mM} \\
-22.20 \cdot 10^{-2} \mathrm{mM} \\
-10.74 \mathrm{mM} \text { in } 0.5 \mathrm{~N} \mathrm{HCl}\end{array}$} \\
\hline 0.3 & 14.19 & & \\
\hline 0.4 & 4.21 & & \\
\hline 0.5 & 9.09 & & \\
\hline
\end{tabular}

concentration of $\mathrm{MBA}$ in the range $6.5 \cdot 10^{-2}$ to $19.45 \cdot 10^{-2} \mathrm{mM}$ while beyond $19.45 \cdot 10^{-2} \mathrm{mM}$, a fall is noticed. The results may be interpreted by the fact that in the initial concentration range of $\mathrm{MBA}$, the increase observed is due to an enhanced hydrophilicity of the matrix, which in turn, attracts a larger number of aniline hydrochloride molecules to diffuse into the gel which upon subsequent polymerization forms greater amount of PANI. However, beyond $19.45 \cdot 10^{-2} \mathrm{mM}$ of MBA, much greater crosslinked network becomes compact and restrains the mobility of both incoming aniline molecules as well as the relaxation of polymer matrix chain. This clearly results in a less amount of PANI impregnation.

\subsubsection{Effect of KPS}

In the present study, the effect of KPS on PANI impregnation has been investigated by varying the concentration of KPS in the range $3.69 \cdot 10^{-2}$ to $14.8 \cdot 10^{-2} \mathrm{mM}$. The results are summarized in Table 1 which clearly reveal that the amount of impregnated PANI increases with increasing KPS in the range $3.69 \cdot 10^{-2}$ to $11.10 \cdot 10^{-2} \mathrm{mM}$ while beyond $11.10 \cdot 10^{-2} \mathrm{mM}$, a fall is obtained. The observed increase may be attributed to the reason that as the concentration of KPS increases, the molecular weight (and also size) of polymer chain decreases which results in a formation of network with large number of pores, but of smaller size, which obviously intakes greater number of AN 
molecules, thus, giving rise to greater impregnation.

However, beyond $11.10 \cdot 10^{-2} \mathrm{mM}$ of KPS, much smaller size of network pores could restrict the diffusion of AN molecules into the polymer gel, and therefore, results in a decrease in the extent of impregnation.

\subsubsection{Effect of AN}

The effect of AN (monomer) concentration on PANI impregnation within the polymer matrix has been studied by varying the concentration of $\mathrm{AN}$ in $0.5 \mathrm{~N} \mathrm{HCl}$ solution in the range 5.3 to $21.48 \mathrm{mM}$ while keeping the concentration of other constitution of the gel as constant. The results are shown in Table 1 which indicate that the extent of PANI impregnation increases with increasing AN content within the matrix while beyond $16.11 \mathrm{mM}$ of aniline concentration, the extent of impregnation decreases. The observed findings may be explained by the fact that as AN is a monomer of PANI, its increasing concentration in the gel will obviously facilitate more polymerization and therefore, extent of impregnation increases. However, beyond a definite concentration, i. e., $16.11 \mathrm{mM}$, the decrease observed in PANI impregnation could be due to a lower degree of swelling in AN hydrochloride solution as much greater ionic concentration (because of aniline hydrochloride ion) in the external solution may result in lower swelling which permits less number of AN molecules for polymerization.

\subsubsection{Effect of APS concentration}

The influence of concentration of APS on PANI impregnation was studied by varying its concentration in the range of 0.2 to $0.5 \mathrm{M}$ keeping other concentration terms constant. The results summarized in Table 1 show that the amount of impregnated PANI decreases with increasing APS concentration. The reason for the observed decrease may be explained by the fact that at low APS concentration, high molecular weight PANI might have been produced whereas at higher APS concentration, the PANI formed would be of lower molecular weight and, therefore, the possibility of leaching of low molecular weight, PANI could not be ruled out. This may consequently result in low impregnation.

\subsection{Electrical conductivity and effects of ingredients}

The electrical conductivity of polymer composite in different weight ratio of ingredients has been studied and it is found that the electrical conductivity of the gel is enhanced after impregnation of PANI. Moreover, the conductivity also varies with the constituents of the polymer matrix as discussed below.

\subsubsection{Effect of PVA}

The effect of PVA content on the conductivity of the matrix has been studied by varying the amount of PVA in the range 1 to $3 \mathrm{~g}$. The results are depicted in Table 2, which reveal that the matrix shows an optimum conductivity at $1 \mathrm{~g}$ of PVA content while a drastic fall of about 10 times is noticed in conductivity when the concentration of PVA increases to $1.5 \mathrm{~g}$. However, beyond $1.5 \mathrm{~g}$ of PVA content, almost no change in conductivity is observed. The results may be explained as below: The conductivity is determined by both the extent of PANI impregnation as well as poly acrylic acid content of the matrix. The former, in turn, is dependent on the hydrophilicity of the matrix. When the concentration of PVA increases from 1 to $1.5 \mathrm{~g}$, the weight fraction of ionic polymer (PAA) decreases in the matrix. This obviously results in fall in conductivity of the matrix. However, beyond $1.5 \mathrm{~g}$ of PVA, increase in PVA content does not bring down the conductivity further, which may be attributed to the fact that the matrix acquire an optimum hydrophilic nature and, therefore, does not show further drop in conductivity.

\subsubsection{Effect of PAA}

In order to study the influence of PAA on the conductivity of the matrix, the concentration of the AA was increased in the range 14.6 to $43.7 \mathrm{mM}$ and electrical conductivity was measured. The results are shown in Table 2, which reveal that the conductivity gradually increases with increasing PAA content in the gel. The results are quite expected and may be explained by the fact that on increasing the concentration of PAA, the number of $\mathrm{COO}^{-}$groups increases along the macromolecular chain which add to the electrical conductivity of the matrix by 
Table 2. Effect of concentration of constituents of the gel on conductivity

\begin{tabular}{|c|c|c|c|c|}
\hline PVA content $[\mathrm{g}]$ & Conductivity native [S/cm] & Conductivity PANI impregnated [S/cm] & & Other ingredients \\
\hline 1.0 & $0.38 \cdot 10^{-2}$ & $3.33 \cdot 10^{-2}$ & \multirow{4}{*}{\multicolumn{2}{|c|}{$\begin{array}{l}\text { AA }-29.1 \mathrm{mM} \\
\text { MBA }-13.0 \cdot 10^{-2} \mathrm{mM} \\
\text { KPS }-7.39 \cdot 10^{-2} \mathrm{mM} \\
\text { APS }-0.3 \mathrm{M} \text { in } 0.5 \mathrm{~N} \mathrm{HCl} \\
\text { AN }-10.74 \mathrm{mM} \text { in } 0.5 \mathrm{~N} \mathrm{HCl}\end{array}$}} \\
\hline 1.5 & $0.19 \cdot 10^{-2}$ & $0.37 \cdot 10^{-2}$ & & \\
\hline 2.0 & $0.27 \cdot 10^{-2}$ & $0.38 \cdot 10^{-2}$ & & \\
\hline 3.0 & $0.56 \cdot 10^{-2}$ & $0.77 \cdot 10^{-2}$ & & \\
\hline AA content $[\mathrm{mM}]$ & Conductivity native [S/cm] & Conductivity PANI impregnated [S/cm] & & Other ingredients \\
\hline 14.6 & $0.63 \cdot 10^{-2}$ & $2.19 \cdot 10^{-2}$ & \multirow{4}{*}{$\begin{array}{l}\text { PVA } \\
\text { MBA } \\
\text { KPS } \\
\text { APS } \\
\text { AN }\end{array}$} & \multirow{4}{*}{$\begin{array}{l}-1 \mathrm{~g} \\
-13.0 \cdot 10^{-2} \mathrm{mM} \\
-\quad 7.39 \cdot 10^{-2} \mathrm{mM} \\
-\quad 0.3 \mathrm{M} \text { in } 0.5 \mathrm{~N} \mathrm{HCl} \\
-10.74 \mathrm{mM} \text { in } 0.5 \mathrm{~N} \mathrm{HCl}\end{array}$} \\
\hline 29.1 & $0.53 \cdot 10^{-2}$ & $2.24 \cdot 10^{-2}$ & & \\
\hline 36.0 & $0.27 \cdot 10^{-2}$ & $2.60 \cdot 10^{-2}$ & & \\
\hline 43.7 & $0.46 \cdot 10^{-2}$ & $2.79 \cdot 10^{-2}$ & & \\
\hline MBA content $[\mathrm{mM}]$ & Conductivity native [S/cm] & Conductivity PANI impregnated [S/cm] & & Other ingredients \\
\hline $6.50 \cdot 10^{-2}$ & $0.01 \cdot 10^{-2}$ & $0.32 \cdot 10^{-2}$ & \multirow{4}{*}{$\begin{array}{l}\text { PVA } \\
\text { AA } \\
\text { KPS } \\
\text { APS } \\
\text { AN }\end{array}$} & \multirow{4}{*}{$\begin{array}{l}-1 \mathrm{~g} \\
-43.7 \mathrm{mM} \\
-\quad 7.39 \cdot 10^{-2} \mathrm{mM} \\
-\quad 0.3 \mathrm{M} \text { in } 0.5 \mathrm{~N} \mathrm{HCl} \\
-10.74 \mathrm{mM} \text { in } 0.5 \mathrm{~N} \mathrm{HCl}\end{array}$} \\
\hline $13.00 \cdot 10^{-2}$ & $0.01 \cdot 10^{-2}$ & $1.27 \cdot 10^{-2}$ & & \\
\hline $19.45 \cdot 10^{-2}$ & $0.11 \cdot 10^{-2}$ & $2.87 \cdot 10^{-2}$ & & \\
\hline $25.90 \cdot 10^{-2}$ & $0.22 \cdot 10^{-2}$ & $2.87 \cdot 10^{-2}$ & & \\
\hline AN content $[\mathrm{mM}]$ & Conductivity native [S/cm] & Conductivity PANI impregnated [S/cm] & & Other ingredients \\
\hline 5.30 & $0.75 \cdot 10^{-2}$ & $5.97 \cdot 10^{-2}$ & \multirow{4}{*}{$\begin{array}{l}\text { PVA } \\
\text { AA } \\
\text { MBA } \\
\text { KPS } \\
\text { APS }\end{array}$} & \multirow{4}{*}{$\begin{array}{l}-1 \mathrm{~g} \\
-43.7 \mathrm{mM} \\
-19.45 \cdot 10^{-2} \mathrm{mM} \\
-11.10 \cdot 10^{-2} \mathrm{mM} \\
-\quad 0.3 \mathrm{M} \text { in } 0.5 \mathrm{~N} \mathrm{HCl}\end{array}$} \\
\hline 10.74 & $0.75 \cdot 10^{-2}$ & $3.59 \cdot 10^{-2}$ & & \\
\hline 16.11 & $0.75 \cdot 10^{-2}$ & $3.84 \cdot 10^{-2}$ & & \\
\hline 21.48 & $0.75 \cdot 10^{-2}$ & $9.10 \cdot 10^{-2}$ & & \\
\hline
\end{tabular}

facilitating conduction of electrons along the PANI chain.

It is also to mention that with increasing concentration of PAA, percent impregnation of PANI also increases in the studied range, which thus, contributes to the observed increase in conductivity.

\subsubsection{Effect of MBA}

In the present investigation, the role of crosslinker has been investigated by varying the amount of crosslinker in the concentration range $6.5 \cdot 10^{-2}$ to $25.9 \cdot 10^{-2} \mathrm{mM}$ and observing the change in electrical conductivity. The results are shown in Table 2, which show that the conductivity sharply increases with increasing concentration of MBA in the range $6.5 \cdot 10^{-2}$ to $19.45 \cdot 10^{-2} \mathrm{mM}$ while after $19.45 \cdot 10^{-2} \mathrm{mM}$ of crosslinker; the conductivity acquires a limiting value.

The observed initial steep increase in conductivity with increasing concentration of MBA may be attributed to the fact that with increasing crosslinker concentration, the network density increases which results in a compact network, thus, facilitating flow of electrons responsible for conductivity behavior. However, beyond an optimum concentration of crosslinking agent, the gels acquire optimum compactness and, therefore, no further increase in conductivity is observed.

\subsubsection{Effect of AN}

The effect of PANI content on the conductivity of the matrix has been investigated by increasing the concentration of aniline in the range 5.3 to $21.48 \mathrm{mM}$ in the feed mixture of the gel. The results are given in Table 2 which indicate that the conductivity increases with increasing concentration of AN. The results are quite obvious and may be explained by the fact that with increasing concentration of AN solution, greater number of AN molecules will be available within the matrix for polymerization and as a subsequence, the extent of impregnation also increases.

\subsection{Bending behaviour of the matrix}

Swollen polyelectrolyte gels when kept under an applied electric field normally exhibit a bending towards the electrodes. This is called Electromechano-chemical (EMC) behavior and has been recognized as a promising phenomenon in designing smart materials. 


\subsubsection{Effect of PANI content}

Inclusion of PANI molecules within the polymer matrix is expected to enhance the EMC behaviour and, therefore, has been studied by varying the PANI content in the range 0 to $30 \%$ at different applied voltages as shown in Figure 11. The results clearly reveal that the effective bending angle (EBA) constantly increases with increasing PANI content. The observed results may be explained by the fact that the greater the PANI content of the matrix, the larger would be the conductivity of the matrix, which in turn, will respond easily to the applied voltage.

It is also noticed from the Figure 11 that at 10 and $30 \%$ of PANI content, the bending is exactly same for a given voltage. The reason for the same bending angle at higher PANI content is that the PANI impregnated matrix acquires optimum conductance and, therefore, shows no further bending. Alternatively, it is also likely that the PANI chains are of the matrix may restrain the bending of the matrix.

The Figure 12 also indicates that the magnitude of effective bending angle also increases with increasing applied voltage across the electrodes. The increase in effective bending angle may be attributed to the fact that with increase in voltage the charged matrix is attracted more and more towards the electrodes and thus, the bending angle increases.

\subsubsection{Effect of voltage}

There is a lower critical voltage (LCV) below which no bending of matrix is observed. In the present study, the LCV is found to be 3.0 volt. Thus, the bending phenomenon is observed only after $3.0 \mathrm{~V}$ and, therefore, the effect of voltage on bending phenomenon has been investigated in the range 6.0 to $12.0 \mathrm{~V}$ for a given PANI content. The influence of applied voltage on the EMC behavior of the matrix has been studied by varying the voltage in the range 6.0 to $12.0 \mathrm{~V}$. The results are depicted in Figures $12 \mathrm{a}, \mathrm{b}$ and $\mathrm{c}$ which indicate that the EMC behavior of the matrix shows an increase in effective bending angle with increasing voltage at $0.1,0.2$ and $0.3 \mathrm{~N} \mathrm{NaCl}$ solution. The observed results are quite obvious as with increasing voltage, the charged matrix shows greater attraction towards electrodes and, therefore, bending angle increases.

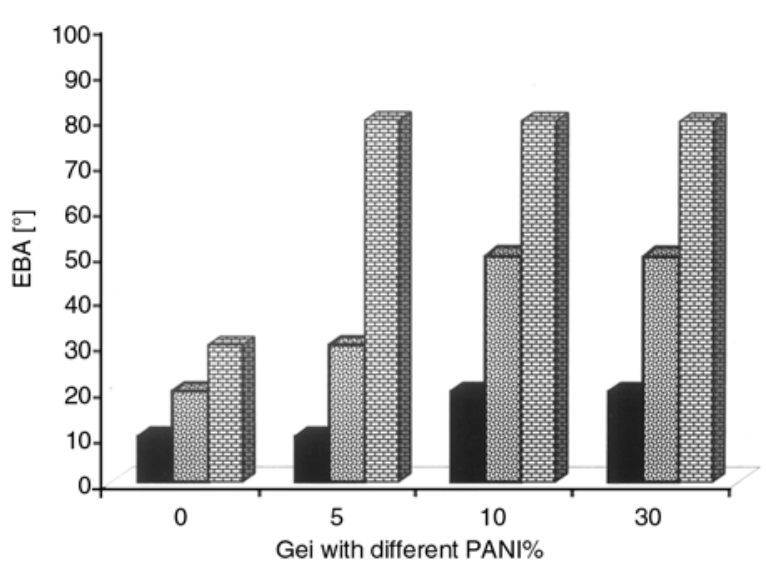

EBA of gel in $0.3 \mathrm{~N} \mathrm{NaCl}$ electrolyte solution 6 Volt DC current 圆 EBA of gel in $0.3 \mathrm{~N} \mathrm{NaCl}$ electrolyte solution 9 Volt DC current 圈 EBA of gel in $0.3 \mathrm{~N} \mathrm{NaCl}$ electrolyte solution 12 Volt DC current

Figure 11. Effect of PANI contents on EBA

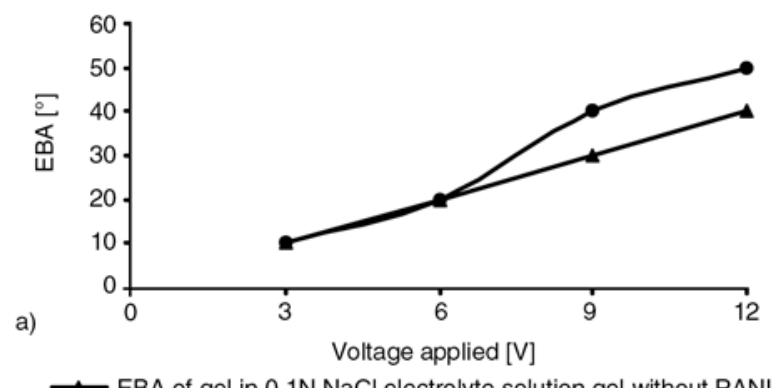

EBA of gel in $0.1 \mathrm{~N} \mathrm{NaCl}$ electrolyte solution gel without PAN EBA of gel in $0.1 \mathrm{~N} \mathrm{NaCl}$ electrolyte solution gel with PANI

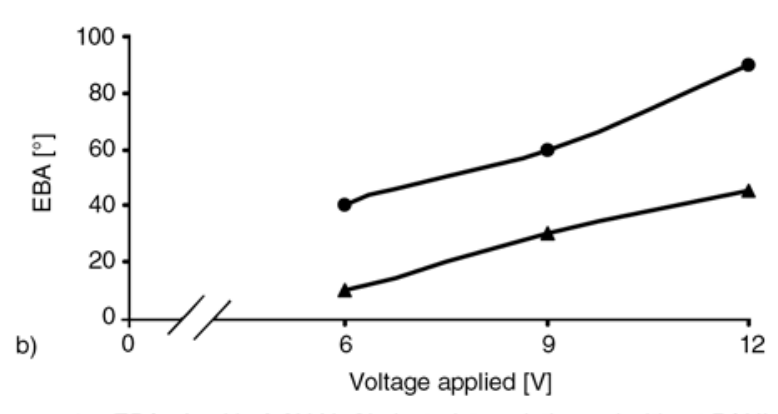

EBA of gel in $0.2 \mathrm{~N} \mathrm{NaCl}$ electrolyte solution gel without PANI EBA of gel in $0.2 \mathrm{~N} \mathrm{NaCl}$ electrolyte solution gel with PANI

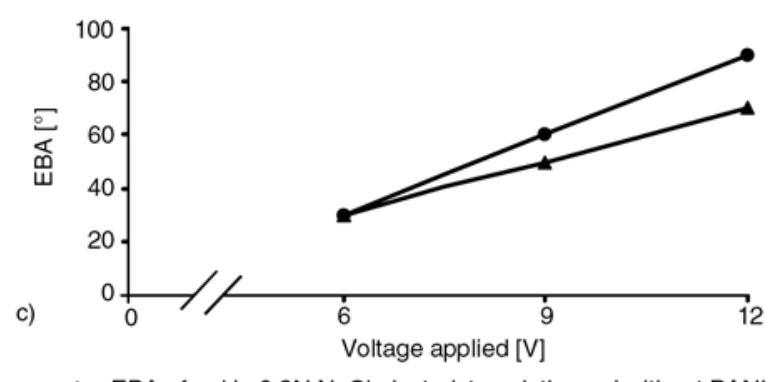

- EBA of gel in $0.3 \mathrm{~N} \mathrm{NaCl}$ electrolyte solution gel without PAN EBA of gel in $0.3 \mathrm{~N} \mathrm{NaCl}$ electrolyte solution gel with PANI

Figure 12. Effects of applied voltage on EBA in
(a) $0.1 \mathrm{~N} \mathrm{NaCl}$ electrolyte solution,
(b) $0.2 \mathrm{~N} \mathrm{NaCl}$ electrolyte solution, and
(c) $0.3 \mathrm{~N} \mathrm{NaCl}$ electrolyte solution 


\subsubsection{Effect of electrolyte concentration}

The concentration of electrolyte solution is an important experimental parameter to exert a significant influence on the effective bending angle of the polymer matrix. The effect of increasing concentration of $\mathrm{NaCl}$ solution on bending of the gel has been studied by varying the concentration of $\mathrm{NaCl}$ in the range 0.1 to $0.3 \mathrm{~N}$. The results are shown in Figures $13 \mathrm{a}, \mathrm{b}$ and $\mathrm{c}$ which reveal that the bending angle substantially increases up to $0.2 \mathrm{~N} \mathrm{NaCl}$ solution and thereafter, it becomes almost constant showing no further increase in bending. The results may be attributed to the fact that increased concentration of $\mathrm{NaCl}$ solution facilitates bending of the polymer matrix by binding salt ion to the polyelectrolyte matrix so as to make it more responsive to the applied field. However, beyond $0.2 \mathrm{~N} \mathrm{NaCl}$

a)

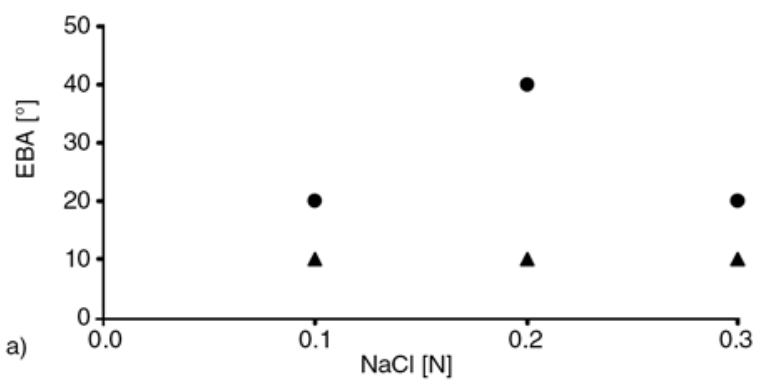

EBA in degree with 6 Volt DC current gel without PANI

EBA in degree with 6 Volt DC current gel without PANI 15\%

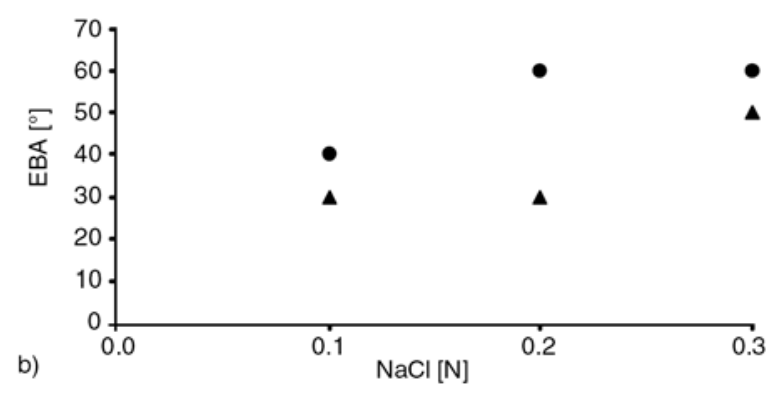

A EBA in degree with 9 Volt DC current gel without PANI

- EBA in degree with 9 Volt DC current gel without PANI 15\%

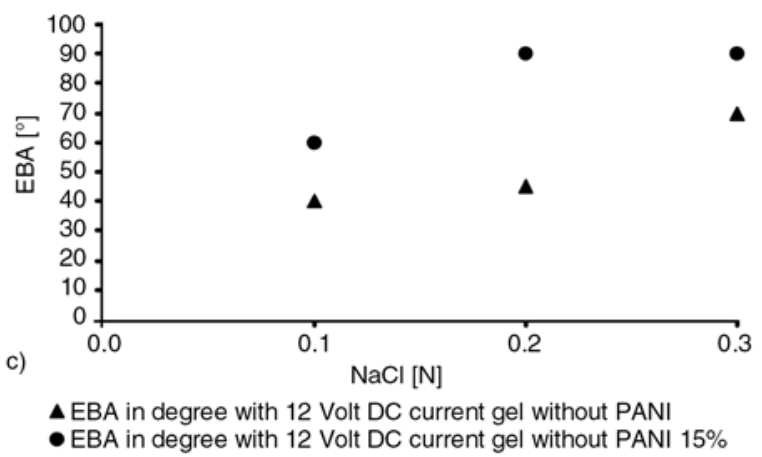

Figure 13. Effect of strength of electrolyte solution in (a) 6 Volt, (b) 9 Volt, and (c) 12 Volt concentration when the charged centers present along the polyelectrolyte molecules are almost completely ionized, further effect on the effective bending angle of the polymer matrix may not likely to occur. This clearly explains the limiting bending of the matrix at highest applied voltage.

\section{Conclusions}

Impregnation of polyaniline into poly(vinyl alcohol)-g-poly(acrylic acid) results in a composite hydrogel which shows fair electroconductive and electroactive behaviors. The FTIR spectra of PANI impregnated hydrogel show characteristic peaks of poly aniline and other functional groups of constituent polymers, i. e., PVA and PAA. The impregnation of PANI into polymer matrix is further confirmed by UV spectral analysis. The impregnation of PANI within the polymer matrix brings about a loss in crystallinity as confirmed by the XRD spectra of the native and PANI impregnated gels. The hydrogel composite shows cluster like morphology varying in size between 0.5 to $2.0 \mu \mathrm{m}$. The polyaniline (PANI) particles undergo aggregation and show a wide variation in their sizes ranging from 1 to $100 \mu \mathrm{m}$.

The extent of PANI impregnation depends on chemical composition of the composite hydrogel. It is noticed that with increasing PVA, MBA, KPS and AN concentration, the amount of PANI impregnation increases up to a certain range and thereafter decreases. On the other hand, whereas an increase in impregnation results with increasing PAA content, a fall in impregnation is observed with increasing APS concentration.

The electrical conductivity also varies with varying composition of the composite. The conductivity increases with increasing PVA and MBA concentration while a drop in conductivity is observed if concentrations are increased further. In the case of AN, the conductivity constantly increases.

The PANI impregnated matrix shows bending behavior when a fixed voltage is applied in the presence of an electrolyte solution $(\mathrm{NaCl})$. The gels show an enhanced bending behavior with increasing PANI content and applied voltage. Moreover, a greater bending is noticed with increasing concentration of electrolyte solution. 


\section{References}

[1] Kajiwara K., Ross-Murphy S. B.: Synthetic gels on the move. Nature, 355, 208-209 (1992).

[2] Kurkuri M. D., Lee J-R., Han J. H., Lee I.: Electroactive behaviour of poly(acrylic acid) grafted poly(vinyl alcohol) samples, their synthesis using a $\mathrm{Ce}^{(\mathrm{IV})}$ glucose redox system and their characterization. Smart Materials and Structure, 13, 417-423 (2006).

[3] Ma J. T., Liu L. R., Yang X. J., Yao K. D.: Bending behaviour of gelatin/poly(hydroxyethyl methacrylate) IPN hydrogel under electric stimulus. Journal of Applied Polymer Science, 56, $73-77$ (1995).

[4] Blanchet G. B., Fincher C. R., Lefenfeld M., Roger J. A.: Contact resistance in organic thin film transistors. Applied Physics Letters, 84, 296-298 (2004).

[5] Tittu M., Hiekkataipale P., Kainen J. H., Makela T. Ikkala O.: Viscoelastic and electrical transitions in gelation of electrically conducting polyaniline. Macromolecules, 35, 5212-5217 (2002).

[6] Akbayir C., Bulut F., Farrell T., Goldschmidt A., Günther R., Kam A. P., Miclea P., Scherf U., Seekamp J., Solovyev V. G., Sotomayor Torres C. M.: Nanostructured conjugated polymeric system for photovoltatic applications. Reviews on Advanced Materials Science, 5, 205-210 (2003).

[7] Tiitu M., Talo A., Forsén O., Ikkala O.: Aminic epoxy resin hardeners as reactive solvents for conjugated polymers: Polyaniline base/epoxy composites for anticorrosion coatings. Elsevier Science (2005). Polymer, 46, 6855-6861 (2005).

[8] Li M., Guo Y., Wei Y., MacDiarmid A. G., Lelkes P. I.: Electrospinning polyaniline-contained gelatin nanofibers for tissue engineering applications. Biomaterials, 27, 2705-2715 (2006).

[9] Kim D-H., Abidian M., Martin D. C.: Conducting polymers grown in hydrogel scaffolds coated on neural prosthetic devices. Journal Of Biomedical Materials Research, Part A, 71, 577-585 (2004).

[10] Qiang Y., Antony J., Sharma A., Nutting J., Meyer D.: Iron/iron oxide core shell nano clusters for biomedical application. Journal of Nanoparticles Research, 8, 489-496 (2005).

[11] Schmid A. L., Torresi. S. I. C., Bassetto A. N., Carlos I. A.: Structural, morphological and spectroelectrochemical characterization of poly(2-ethyl aniline). Journal of the Brazil Chemical Society, 11, 317-323 (2000).

[12] Ansari R., Keivani M. B.: Polyaniline conducting electroactive polymers, thermal and environmental stability studies. Journal of Chemistry, 3, 202-217 (2006).

[13] Ryu K. S., Chang S. H., Kang S-G., Oh E. J., Yo C. H.: Physicochemical and electrical characterization of polyaniline induced by crosslinking, stretching and doping. Bulletin of the Korean Chemical Society, 20, 333-336 (1999).
[14] Jang S-Y., Seshadri V., Khil M-S., Kumar A., Marquez M., Mather P. T., Sotzing G. A.: Welded electrochromic conductive polymers nanofibres by electrostatic spinning. Advanced Material, 17, 2177-2180 (2005).

[15] Deore B. A., Yu I., Anguiar P. M., Siedler C. R., Freund M. S.: Highly crosslinked, self doped polyaniline exhibiting unprecedented hardness. Chemical Materials, 17, 3803-3805 (2005).

[16] Huang J.: Synthesis and applications of conducting polymer polyaniline nanofibers. Pure and Applied Chemistry International, 78, 15-27 (2006).

[17] Tang B. Z., Geng Y., Sun Q., Zhang X. X., Jing X.: Processible nanomaterials with high conductivity and magnetizability: Preparation and properties of magnemite/poly aniline nanocomposites film. Pure Application Chemistry, 72, 157-162 (2000).

[18] Hussain A. M. P., Kumar A.: Electrochemical synthesis and characterization of chloride doped polyaniline. Bulletin of Material Science, 26, 329-334 (2003).

[19] Ibrahim M., Koglin E.: Spectroscopic study of polyaniline emeraldine base: Modelling approach. Acta Chimica Slovenica, 52, 159-163 (2005).

[20] Liu G., Freund M. S.: New approach for the controlled crosslinking of polyaniline: Synthesis and characterization. Macromolecules, 30, 5660-5665 (1997).

[21] Oh K. W., Kim S. H., Kim E. A.: Improved surface characteristic and the conductivity of polyanilinenylon fabrics by plasma treatment. Journal of Applied Polymer Science, 81, 684-694 (2001).

[22] Wang Y., Jing X.: Intrinsically conducting polymers for electromagnetic interference shielding. Polymer for Advanced Technologies, 16, 344-351 (2005).

[23] da Silva P. J. E., Temperini M. L. A., Torresi S. I. C.: Characterization of conducting polyaniline blends by resonance. Journal of Brazil Chemical Society, 16, 322-327 (2005).

[24] Plesu N., Hiescu S., Ilia G., Popa A., Muntean C.: Rheology of polyaniline aispersims in acrylic resin. Turkey Journal of Chemistry, 30, 155-163 (2006).

[25] Draman S. F. S., Daik R., Ahmad M.: Fluorescence characteristics of sulfonated polyaniline solution in DMF when exposed to oxygen gas. Malaysian Journal of Chemistry, 8, 37-44 (2006).

[26] Steyskal J., Gilberg, K. G.: Polyaniline, preparation of a conducting polymer (IUPAC Technical Report). Pure and Applied Chemistry, 74, 857-867 (2002).

[27] Vilènik M., igon M., Zupan M., Šebenik A.: Influence of polymerization parameters in the molecular weight of polyaniline. Acta Chimica Slovenica, 45, 173-183 (1998).

[28] Li D., Kaner R. B.: Shape and aggregation control of nanoparticles: Not shaken not stirred. Journal of American Chemical Society, 128, 968-975 (2006).

[29] Pérez R., Pinto N. J.: Electrical characterization of polyaniline synthesized using one phase emulsion polymerization process. in 'Proceeding of the National Conference on Undergraduate Research (NCUR) 2004, Indianapolis, USA’ 15-17 (2004). 
[30] Arsalani N., Khavei M., Entezanai A. A.: Synthesis and characterization of novel-N-substituted polyaniline by Triton X-100. Iranian Polymer Journal, 12, 237-242 (2003).

[31] Gaikwad P. D., Shirale D. J., Gade V. K., Savale P. A., Kharat H. J., Kakde K. P., Hussaini S. S., Dhumane N. R., Shirsat M. D.: Synthesis of $\mathrm{H}_{2} \mathrm{SO}_{4}$ doped polyaniline film by potentiometric method. Bulletin of Material Science, 29, 169-172 (2006).

[32] Mallick K., Witcomb M. J., Binsmore A., Scurrell M. S.: Polymerization of aniline by cupric sulfate: A facile synthetic route for producing polyaniline. Journal of Polymer Research, 13, 397-401 (2006).

[33] Nestorovic G. D., Jeremic K. B., Jovanovic S. M..: Kinetics of aniline polymerization initiated with Iron III chloride. Journal of Serbian Chemical Society, 71, 895-904 (2006).

[34] Gupta V., Miura N.: Electrochemically deposited polyanilins network: A high performance electrode materials for redox super capacitors. Electrochemical and Solid State Letters, 8, A630-A632 (2005).

[35] Mazur M., Tagowska M., Palys B., Jackowska K.: Template synthesis of poly aniline and poly(2methoxy aniline) nanotubes: Comparison of the formation mechanism. Electrochemistry Communications, 5, 403-407 (2003).

[36] Dispenza C., Lo Presti C., Belfione C., Spadaro G., Piazza S.: Electrically conductive hydrogel composites made of polyaniline nanoparticles and poly $(\mathrm{N}$ vinyl-2-pyrrolidone). Polymer, 47, 961-971 (2006).

[37] Savitha P., Swapna Rao P., Sathyanarayana D. N.: Highly conductive new aniline copolymers: poly(aniline-co-amino acetophenone)s. Polymer International, 54, 1243-1250 (2005).
[38] Pant H. C., Patra M. K., Negi S. C., Bhatia A., Vadera S. R., Kumar, N.: Studies on conductivity and dielectric properties of polyaniline-zinc sulphide composites. Bulletin of Material Science, 29, 379-384 (2006).

[39] Shantala P., Raghavendra S. D. P., Revansiddappa S., Narsimha P., Ambika Prasad M.: Synthesis, transport and dielectric properties of polyaniline/ $\mathrm{Co}_{3} \mathrm{O}_{4}$ composites. Bulletin of Material Science, 30, 89-92 (2007).

[40] Lee K. S., Blanchet G. B., Gao F., Loo Y-L.: Direct patterning of conductive water-soluble polyaniline for thin film organic electrodes. Applied Physics Letters, 86, 076102/1-076102/3 (2005).

[41] Pud A., Ogurtsov N., Korzhenko A., Shapoval G.: Some aspects of preparation methods and properties of polyaniline blends and composites with organic polymers. Program Polymer Science, 28, 1701-1753 (2003).

[42] Shukla S., Bajpai A. K.: Preparation and characterization of highly swelling smart grafted polymer networks of poly (vinyl alcohol) and poly (acrylic acid-co-acrylamide). Journal Applied Polymer Science, 102, 84-95(2006).

[43] Bajpai A. K., Mishra A.: Preparation and characterization of tetracycline-loaded interpenetrating polymer networks of carboxymethyl cellulose and poly (acrylic acid): Water sorption and drug release study. Polymer International, 54, 1347-1356 (2005).

[44] Bajpai A. K., Saini R.: Preparation and characterization of biocompatible spongy cryogels of poly (vinyl alcohol)-gelatin and study of water sorption behaviour. Polymer International, 54, 1233-1242 (2005). 